\title{
EXPERIMENTAL INVESTIGATIONS ON CONCRETE EDGE FAILURE OF MULTIPLE ROW ANCHORAGES WITH SUPPLEMENTARY REINFORCEMENT
}

\author{
AKANSHU SHARMA ${ }^{*}$, ROLF ELIGEHAUSEN ${ }^{\dagger}$ AND JÖRG ASMUS ${ }^{\dagger \dagger}$ \\ Institute for construction materials, \\ University of Stuttgart, Germany \\ e-mail: akanshu.sharma@iwb.uni-stuttgart.de \\ ${ }^{\dagger}$ Institute for construction materials, \\ University of Stuttgart, Germany \\ e-mail: eligehausen@gmx.de \\ IEA, Engineering office Eligehausen-Asmus-Hofmann \\ Stuttgart, Germany \\ e-mail: $\underline{\text { asmus@i-ea.de }}$
}

Key words: Anchorages, concrete edge failure, failure crack, supplementary reinforcement, experiments

\begin{abstract}
This paper presents the details and results of the experimental investigations performed on the anchorages with multiple anchor rows of headed studs close to the edge, without and with supplementary reinforcement, loaded in shear towards the edge. The tests were performed on anchorages with 2 to 8 headed studs (one to 4 anchor rows) cast in concrete with 4 different levels of supplementary reinforcement. The test results highlight the influence of supplementary reinforcement on load carrying capacity of the anchorages. It is observed that for anchorages with multiple anchor rows, the failure crack always initiates from the back row of anchors, which is in contrast to the current assumption in EN1992-4 [1]. Due to this, more number of stirrups is activated in reality and the anchorage length of the activated stirrups is significantly more than that assumed in current model of EN1992-4. Consequently, for low amounts of supplementary reinforcement, the failure loads calculated by the current model are very conservative when compared to the experimental results. At high amounts of supplementary reinforcement, the concrete strut failure may govern the failure, which is ignored in the current models. Based on the evaluation of these test results, and supporting finite element calculations using 3D FE software MASA developed at University of Stuttgart, a realistic and rational model has been developed to predict the concrete edge failure loads for anchorages with supplementary reinforcement that is presented in accompanying paper.
\end{abstract}

\section{INTRODUCTION}

An anchor group without supplementary reinforcement subjected to shear loads perpendicular to an edge may fail by concrete edge failure, anchor steel failure or pryout failure. In case of anchorages close to an edge, loaded in shear perpendicular to and towards the edge, concrete edge failure often dominates. For the case of anchorages with multiple anchor rows perpendicular to the edge, the failure load corresponding to concrete edge failure is permitted to be calculated either by assuming the failure crack 
initiating from the front anchor row (according to prEN 1992-4 [1]) or by assuming the failure crack initiating from back anchor row (according to ACI 318 [2] and fib Bulletin 58 [3]). The assumption of failure crack from front anchors [1] essentially implies that the same design failure load corresponding to concrete edge failure is estimated for a group of single anchor row or multiple anchor rows if the edge distance for the first row of anchors and the other parameters remain same (Compare Fig. 1). In this case, for anchor steel failure, all anchors are considered to contribute equally to take up a shear load applied concentrically to the anchorage.

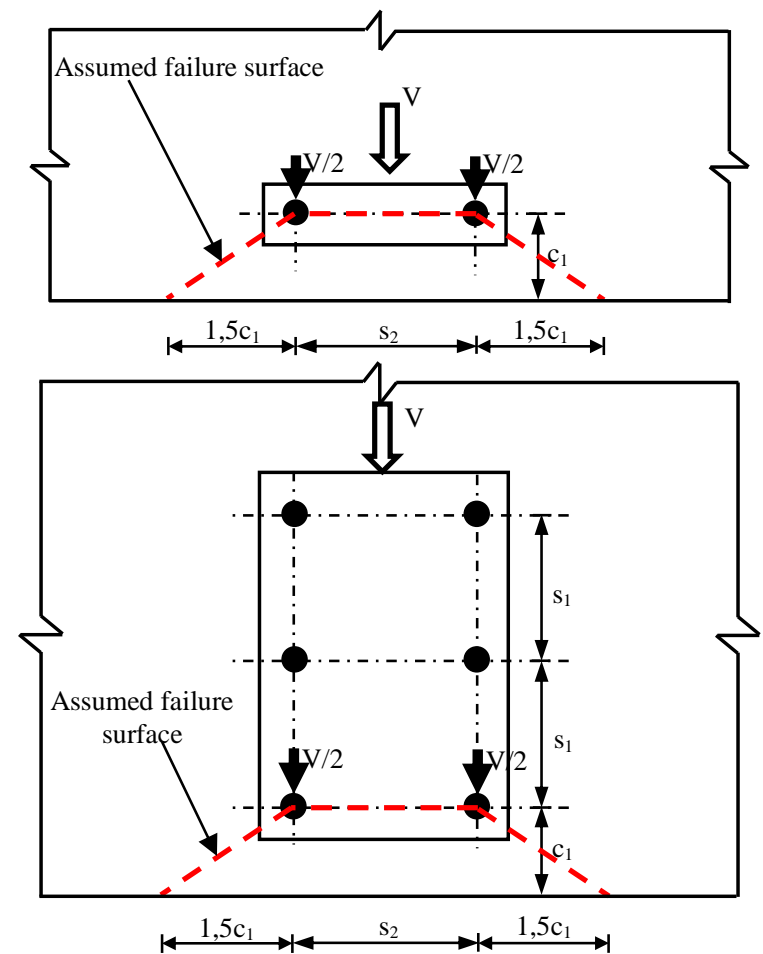

Figure 1: Current assumption of design failure surface for concrete edge failure according to EN1992-4 [1]

The assumption of load transfer only by the first row of anchors is conservative because the redistribution of the shear load to the back anchors after the first hairline cracks due to the concrete edge failure of the front anchors is neglected. In reality, the final failure occurs by a crack starting from the back anchors. Due to the larger edge distance of the back anchors, the concrete edge failure load is significantly higher than that evaluated assuming failure crack from the front anchors. ACI 318 [2] and fib bulletin 58 [3] recognize this and allow evaluating the failure load corresponding to concrete edge failure for anchorages without supplementary reinforcement by assuming the failure crack originating from the farthest anchor row. However, if this assumption is utilized to evaluate the failure load corresponding to concrete edge failure, the anchor steel failure load must be calculated assuming that the total shear load is carried only by the anchors in the last row of the anchorage alone [2-3].

The presence of anchor (supplementary) reinforcement, in the form of edge reinforcement and stirrups, can have a significant influence on the load-carrying capacity of the anchorage subjected to shear loads perpendicular to the edge. In case of an anchor group in reinforced concrete, the possible failure modes can be listed as (i) Steel failure of anchor, (ii) Yielding of stirrups (following the concrete cracking), (iii) Strut (compression) failure, and (iv) Node (anchorage) failure. Currently, strut failure is neglected and a very conservative approach to consider the steel failure of anchor, stirrup yielding and node failure is given in EN1992-4 [1].

The failure load corresponding to concrete edge failure followed by stirrup yielding is calculated assuming the failure crack originating from the front row of anchors (Figure 2). Due to this assumption, only the stirrups close to the anchor group are considered as active (stirrups A in Figure 2) while the stirrups farther away are ignored. Furthermore, a small anchorage length of the stirrups intercepted by the crack is calculated which results in a small capacity of the hook. Therefore, due to this assumption, the capacity evaluated by the current models is very conservative for groups with more than one anchor row. On the other hand, if the failure crack is assumed to initiate from the back row of anchors, more stirrups will be activated due to interception by the crack (stirrups A and B in Figure 2) and also a larger anchorage length is calculated for stirrups A resulting in a higher anchorage capacity of the stirrups. However, there is only limited research performed to 
investigate the anchorage capacity of anchor reinforcement and its influence on the failure load.

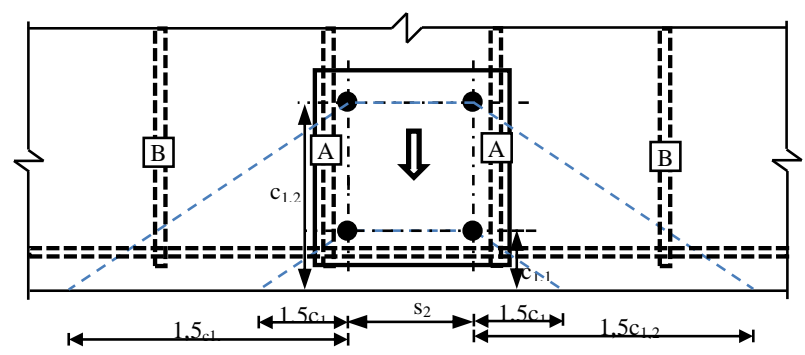

Figure 2: Influence of assumption of failure crack on stirrup contribution

Additionally, the enhancement in the capacity of the anchorages due to the presence of reinforcement is considered only when the anchor reinforcement exceeds a certain minimum reinforcement. In reality however, even lesser amounts of reinforcement than the minimum value contribute towards enhanced load carrying capacity.

Although, the capacity of the anchorage under shear loading can be increased by providing anchor reinforcement, this increase is not unlimited. This is due to the fact that after a certain limit, the concrete strut becomes the weak link and starts governing the failure load. This is the absolute upper limit for the concrete edge resistance of an anchorage group. However, so far, there is no information on this limit due to strut failure and consequently EN1992-4 [1] does not give any guidance to consider it.

In this work, experiments are performed on anchor groups with 2 to 8 headed studs cast in unreinforced and reinforced concrete, loaded in shear perpendicular to the edge to study their behavior in case of concrete edge failure. The evaluation of the test results clearly demonstrate that the current models are overconservative in estimating the failure loads for unreinforced concrete as well as for low to medium percentage of reinforcement. However, for high percentages of reinforcement, the current models are prone to over-predict the failure load as they do not recognize strut failure as a possible failure mode.

\section{TEST PROGRAM}

Four different anchor group configurations were used for the experimental investigations. The groups are identified as (i) $1 \times 2$ group with one row of two headed studs; (ii) $2 \times 2$ group with two rows of two headed studs in each row; (iii) $4 \times 2$ group with four rows of two headed studs in each row; and (iv) $2 \times 4$ group with two rows of four headed studs in each row. The test program followed is given in Table 1. In each case, the edge distance to the first anchor row was kept as $c_{1,1}=85 \mathrm{~mm}$.

Table 1: Test Program

\begin{tabular}{|c|c|c|c|c|c|c|c|}
\hline $\begin{array}{c}\text { S. } \\
\text { No. }\end{array}$ & $\begin{array}{c}\text { Dia. of } \\
\text { stirrups } \\
(\mathrm{mm})\end{array}$ & Id. & $n_{\text {row }}$ & $n_{\text {col }}$ & $\begin{array}{c}\mathrm{s}_{1} \\
(\mathrm{~mm})\end{array}$ & $\begin{array}{c}\mathrm{s}_{2} \\
(\mathrm{~mm})\end{array}$ & $\begin{array}{c}\text { No. of } \\
\text { tests }\end{array}$ \\
\hline 1 & \multirow{4}{*}{0} & $1 \times 2$ & 1 & 2 & -- & 150 & 3 \\
\hline 2 & & $2 \times 2$ & 2 & 2 & 150 & 150 & 3 \\
\hline 3 & & $4 \times 2$ & 4 & 2 & 150 & 150 & 3 \\
\hline 4 & & $2 \times 4$ & 2 & 4 & 150 & 150 & 3 \\
\hline 5 & \multirow{4}{*}{12} & $1 \times 2$ & 1 & 2 & -- & 150 & 3 \\
\hline 6 & & $2 \times 2$ & 2 & 2 & 150 & 150 & 3 \\
\hline 7 & & $4 \times 2$ & 4 & 2 & 150 & 150 & 3 \\
\hline 8 & & $2 \times 4$ & 2 & 4 & 150 & 150 & 3 \\
\hline 9 & \multirow{3}{*}{16} & $1 \times 2$ & 1 & 2 & -- & 150 & 3 \\
\hline 10 & & $2 \times 2$ & 2 & 2 & 150 & 150 & 4 \\
\hline 11 & & $4 \times 2$ & 4 & 2 & 150 & 150 & 3 \\
\hline 12 & \multirow{4}{*}{$16+14$} & $1 \times 2$ & 1 & 2 & -- & 150 & 3 \\
\hline 13 & & $2 \times 2$ & 2 & 2 & 150 & 150 & 3 \\
\hline 14 & & $4 \times 2$ & 4 & 2 & 150 & 150 & 3 \\
\hline 15 & & $2 \times 4$ & 2 & 4 & 150 & 150 & 3 \\
\hline
\end{tabular}

The concrete slabs were provided with edge reinforcement and stirrups of diameter, $\mathrm{d}_{\mathrm{s}}=$ $0 \mathrm{~mm}$ (unreinforced concrete), $12 \mathrm{~mm}, 16 \mathrm{~mm}$ and bundled reinforcement using $16 \mathrm{~mm}$ and $14 \mathrm{~mm}$ reinforcing bars. The tests were performed in the laboratory of Institute of Construction Materials, University of Stuttgart, Germany.

The shear load was applied to the anchor plate through an $80 \mathrm{~mm}$ thick shear loading plate, which was connected to a shear loading fork. In order to minimize friction, $2 \mathrm{~mm}$ thick Teflon sheets were placed below the shear loading fork. The shear loading plate did not touch the concrete surface. The load transfer between the shear loading plate and the anchor plate was facilitated through M24 bolts 
threaded into internally threaded holes, predrilled in the base plate. The uplift of the base plate was restrained during the tests. Figure 3 displays the typical test setup utilized to perform the experiments.

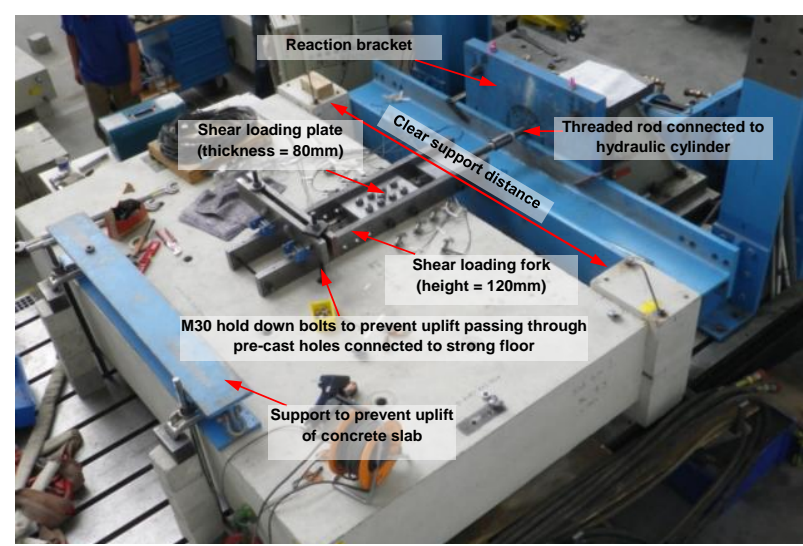

(a) Test Setup

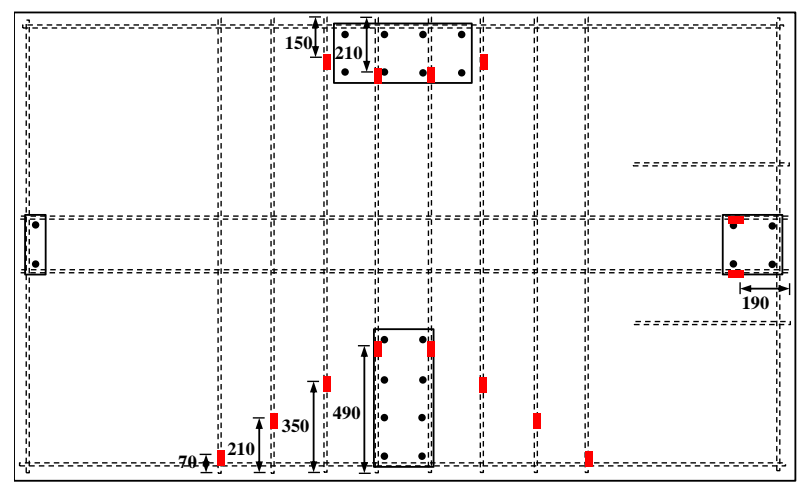

(b) Strain Gauge Locations

Figure 3: Test setup utilized for performing the experiments

In order to estimate the tensile forces taken up by stirrups and hence segregate the individual contribution of stirrups and concrete, strain gauges at specified locations (Figure 3b) were provided in 2 slabs reinforced with ds $12 \mathrm{~mm}$ reinforcing bars. The location of the strain gauges correspond to the location of intersection of the stirrup with the theoretical crack assumed from the back row of anchors. No strain gauges were applied for the groups $1 \times 2$.

All the headed studs had a diameter of $22 \mathrm{~mm}$. The base plate had a thickness of $25 \mathrm{~mm}$ and the stud lengths were such that the effective embedment depth of the anchors was $190 \mathrm{~mm}$. The average cubic concrete strength was obtained as $26.4 \mathrm{MPa}$, while the mean yield stress and mean ultimate stress for the reinforcing bars was obtained as $532 \mathrm{MPa}$ and $573 \mathrm{MPa}$ respectively. The mean ultimate strength of the headed studs was $518 \mathrm{MPa}$.

\section{EXPERIMENTAL RESULTS}

This section summarizes the loaddisplacement curves obtained from the tests performed in concrete slabs with different types of reinforcement for (a) Groups $1 \times 2$, (b) Groups 2x2, (c) Groups 4x2 and (d) Groups $2 \times 4$. In the load-displacement plots, the curves are identified with the nomenclature as ds (diameter of stirrup)_(group name)_(number of test).

\subsection{Group 1x2}

For group 1 x 2, due to small anchorage length of the stirrups, the contribution of reinforcement mainly came from the rope action offered by the edge reinforcement. However, this contribution is unreliable as can be seen from Figure 4, where the resistance in case of $16 \mathrm{~mm}$ stirrups is higher than in case of $16+14 \mathrm{~mm}$ bundled stirrups.

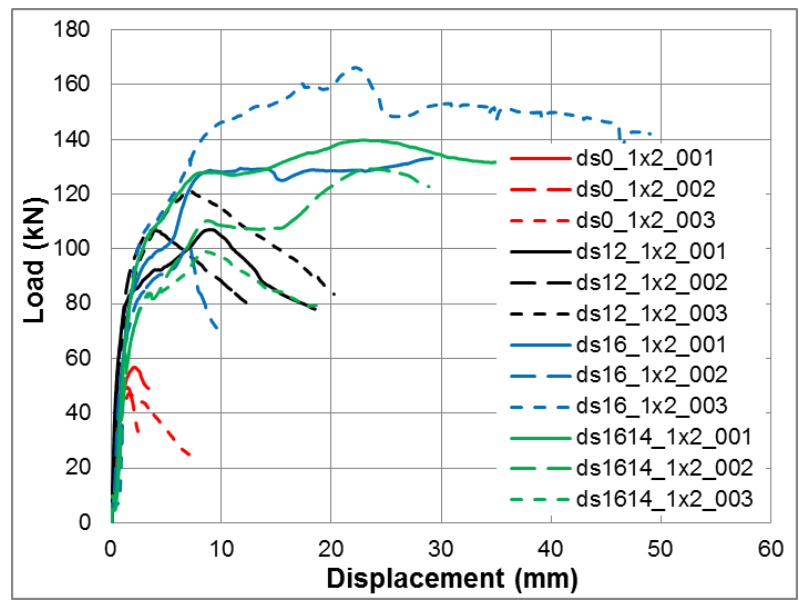

Figure 4: Load-displacement plots obtained from the tests on $1 \times 2$ groups

The typical failure mode observed from the tests performed on groups $1 \times 2$ is shown in Figure 5. Since there is only one anchor row, the failure crack initiates from this row. For better visibility, position of the stirrups is marked on concrete by red lines. 


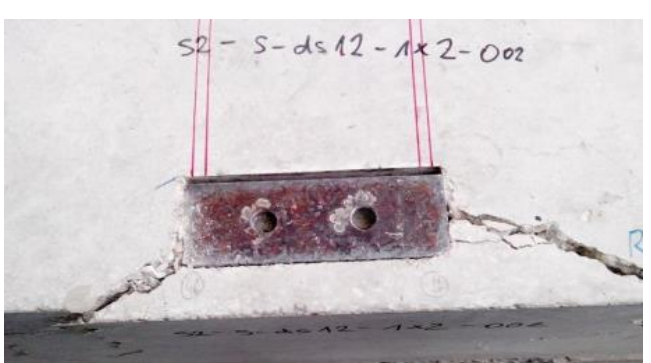

Figure 5: Typical failure mode obtained for $1 \times 2$ groups

\subsection{Group $2 \times 2$}

The load-displacement curves obtained for the $2 \times 2$ groups are shown in Figure 6, while the typical failure mode is displayed in Figure 7. The position of the stirrups is marked on concrete by red lines. In case of groups $2 \times 2$, even though the initial crack appeared from the front anchor row, the failure crack initiated from the back anchor row. Due to this, the stirrups have relatively large anchorage length and therefore a high contribution comes even at relatively low amount of reinforcement with the stirrups of $12 \mathrm{~mm}$ diameter. On further increase in the reinforcement percentage, the failure load further increases but the rise is not so strong and the failure load seems to get saturated. This points out to the fact that there is an upper limit to the beneficial effect of the supplementary reinforcement on the failure load. For this group, the upper limit of the failure load in reinforced concrete is of order of 2.8 times the failure load in unreinforced concrete.

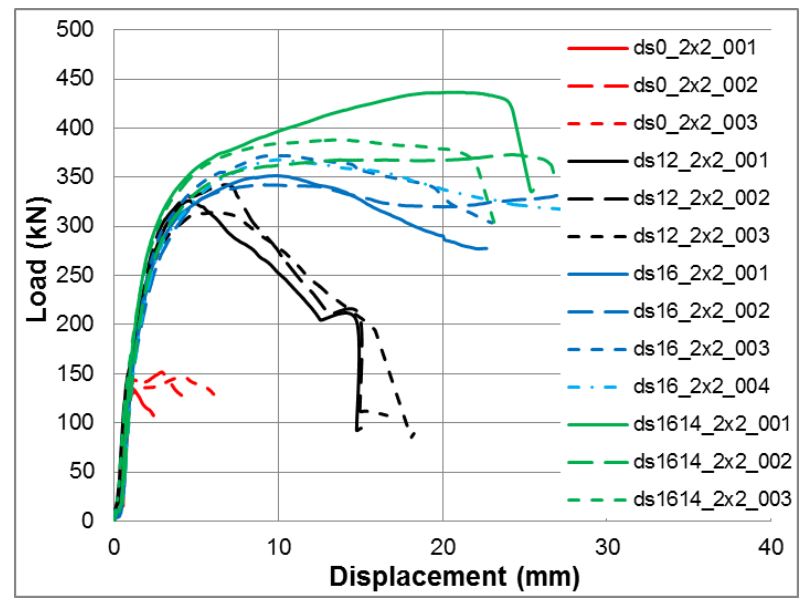

Figure 6: Load-displacement plots obtained from the tests on $2 \times 2$ groups

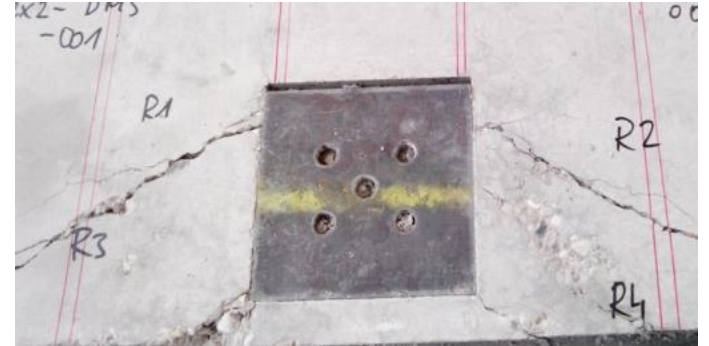

Figure 7: Typical failure mode obtained for $2 \times 2$ groups

\subsection{Group $4 \times 2$}

The load-displacement curves obtained from the tests on $4 \times 2$ anchor groups, with four anchor rows having two anchors in a row, are shown in Figure 8. Again an addition of a relatively small amount of reinforcement (12 mm stirrups) leads to a significant increase in the failure load compared to the tests in unreinforced concrete. However for this case, in contrast to the earlier two cases, further increasing the diameter of stirrups from $12 \mathrm{~mm}$ to $16 \mathrm{~mm}$ also led to a reasonable increase in failure loads suggesting that reinforcement failure continued to govern the failure mode. Increasing the reinforcement using $16+14 \mathrm{~mm}$ bundled stirrups also led to a further increase in failure load but this increase was not proportional and the failure load seems to get saturated. For this group, the upper limit of the failure load in reinforced concrete is of order of 2.6 times the failure load in unreinforced concrete. The crack pattern in Figure 9 shows the failure crack appearing from the back row of the anchors.

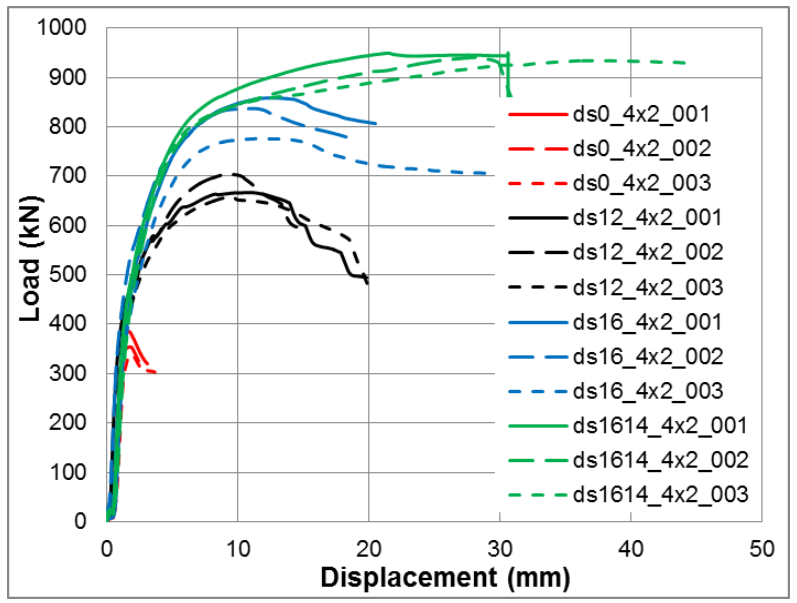

Figure 8: Load-displacement plots obtained from the tests on $4 \times 2$ groups 


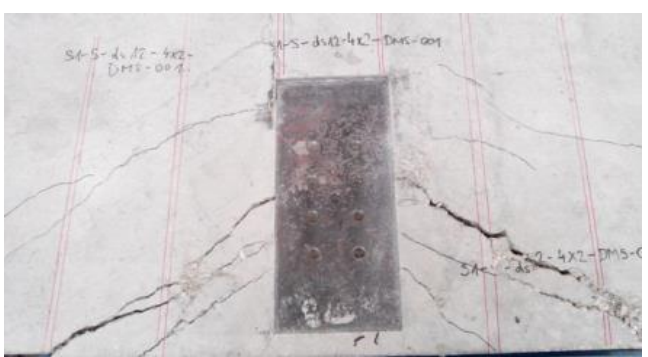

Figure 9: Typical failure mode obtained for $4 \times 2$ groups

\subsection{Group 2x4}

The load-displacement curves obtained from the tests on $2 \times 4$ anchor groups, with two anchor rows having four anchors in a row, are shown in Figure 10. In case of $2 \times 4$ anchor groups, the tests were performed only with $12 \mathrm{~mm}$ stirrups and $16+14 \mathrm{~mm}$ bundled stirrups. Again an addition of a relatively small amount of reinforcement (12mm stirrups) led to a significant increase in the failure load compared to the tests in unreinforced concrete. However for this case, in contrast to the earlier cases, increasing the reinforcement using $16+14 \mathrm{~mm}$ bundled stirrups resulted in the failure load of the order of 4.3 times the failure load in unreinforced concrete. The crack pattern in Figure 11 clearly shows the failure crack appearing from the back row of the anchors.

\subsection{Summary of experimental results}

The summary of the influence of reinforcement on mean failure loads for different anchor groups is given in table 2.

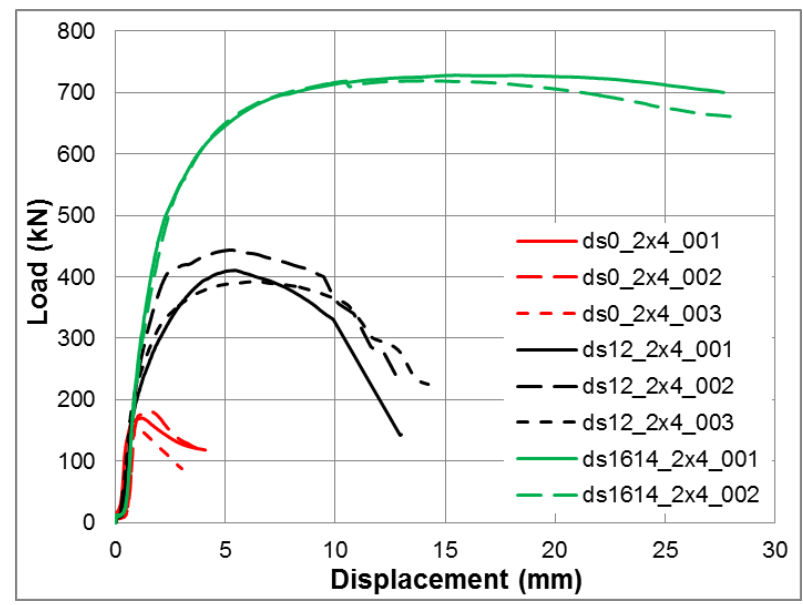

Figure 10: Load-displacement plots obtained from the tests on $2 \times 4$ groups

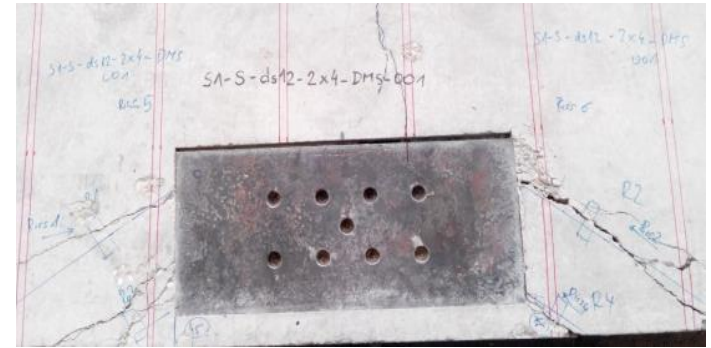

Figure 11: Typical failure mode obtained for $4 \times 2$ groups

Table 2: Summary of Test Results

\begin{tabular}{|c|c|c|c|c|}
\hline 1 & 2 & 3 & 4 & 5 \\
\hline Id. & $\begin{array}{l}\text { C.s. area of } \\
\text { one stirrup } \\
\quad\left(\mathrm{mm}^{2}\right)\end{array}$ & $\begin{array}{c}\text { Mean } \\
\text { failure } \\
\text { load } \\
(\mathrm{kN})\end{array}$ & \begin{tabular}{|c} 
Ratio of \\
failure load \\
to failure \\
load in \\
plain \\
concrete
\end{tabular} & $\begin{array}{l}\text { Failure } \\
\text { mode }\end{array}$ \\
\hline \multirow{4}{*}{$1 \times 2$} & 0 (Plain) & 51.2 & 1.0 & $\begin{array}{c}\text { Concrete } \\
\text { edge }\end{array}$ \\
\hline & $113(12 \mathrm{~mm})$ & 111.7 & 2.2 & $\begin{array}{l}\text { Edge } \\
\text { rebar }\end{array}$ \\
\hline & $201(16 \mathrm{~mm})$ & 133.5 & 2.6 & $\begin{array}{l}\text { Edge } \\
\text { rebar }\end{array}$ \\
\hline & $\begin{array}{c}355 \\
(16+14 \mathrm{~mm})\end{array}$ & 122.7 & 2.4 & $\begin{array}{l}\text { Edge } \\
\text { rebar }\end{array}$ \\
\hline \multirow{4}{*}{$2 \times 2$} & 0 (Plain) & 144.3 & 1.0 & $\begin{array}{c}\text { Concrete } \\
\text { edge }\end{array}$ \\
\hline & $113(12 \mathrm{~mm})$ & 327.5 & 2.3 & $\begin{array}{c}\text { Stirrup } \\
\text { yielding }\end{array}$ \\
\hline & $201(16 \mathrm{~mm})$ & 367.7 & 2.6 & $\begin{array}{c}\text { Concrete } \\
\text { Strut }\end{array}$ \\
\hline & $\begin{array}{c}355 \\
(16+14 \mathrm{~mm}) \\
\end{array}$ & 399.2 & 2.8 & $\begin{array}{c}\text { Concrete } \\
\text { Strut }\end{array}$ \\
\hline \multirow{4}{*}{$4 \times 2$} & 0 (Plain) & 359.9 & 1.0 & $\begin{array}{c}\text { Concrete } \\
\text { edge }\end{array}$ \\
\hline & $113(12 \mathrm{~mm})$ & 675.8 & 1.9 & $\begin{array}{l}\text { Stirrup } \\
\text { yielding }\end{array}$ \\
\hline & $201(16 \mathrm{~mm})$ & 823.8 & 2.3 & $\begin{array}{c}\text { Stirrup } \\
\text { yielding }\end{array}$ \\
\hline & $\begin{array}{c}355 \\
(16+14 \mathrm{~mm}) \\
\end{array}$ & 941.3 & 2.6 & $\begin{array}{c}\text { Concrete } \\
\text { Strut }\end{array}$ \\
\hline \multirow{3}{*}{$2 \times 4$} & 0 (Plain) & 169.5 & 1.0 & $\begin{array}{c}\text { Concrete } \\
\text { edge }\end{array}$ \\
\hline & $113(12 \mathrm{~mm})$ & 415.5 & 2.5 & $\begin{array}{c}\text { Stirrup } \\
\text { Yielding }\end{array}$ \\
\hline & $\begin{array}{c}355 \\
(16+14 \mathrm{~mm}) \\
\end{array}$ & 723.4 & 4.3 & $\begin{array}{c}\text { Concrete } \\
\text { Strut }\end{array}$ \\
\hline
\end{tabular}

The column 4 of Table 2 gives the values of mean failure loads for each group normalized 
to the mean failure load obtained from the tests on corresponding group in unreinforced concrete. In column 5 of Table 2, the failure modes are given.

For all the groups with only two anchors in a row (group $1 \times 2$, group $2 \times 2$ and group $4 \times$ 2), the failure load could be increased up to 2.8 times the failure load in unreinforced concrete. This value is close to the highest value recommended by Berger [4] for anchorages under tension loads for strut failure. However, for the case of the anchor group $2 \times 4$ with four anchors in a row, the maximum failure load could be increased to almost 4.3 times the mean failure load observed in unreinforced concrete, by providing additional reinforcement. This suggests that anchorages with more than two anchor columns may have a higher strut failure capacity than groups with one or two anchor columns, for the same reinforcement configuration.

\section{COMPARISON WITH EN1992-4 MODEL}

\subsection{Model given in EN1992-4 [1]}

According to EN1992-4 [1], in case of anchorages with anchor reinforcement in form of stirrups and edge reinforcement, the load corresponding to failure of reinforcement in the concrete breakout body can be obtained on the basis of the strut-and-tie model as shown in Figure 12.

As per EN1992-4 [1], if the shear force is taken up by anchor reinforcement according to Figure 12, the following requirements should be met:

i. Only bars with a distance $\leq 0.75 \mathrm{c} 1$ from the fastener should be assumed as effective.

ii. The anchorage length $l_{1}$ (Figure 12) in the concrete breakout body is at least equal to 10 times the rebar diameter (straight bars with or without welded transverse bars) or at least equal to 4 times the rebar diameter (bars with a hook, bend or loop).

iii. Reinforcement along the edge of the member should be provided and be designed for the forces according to an appropriate strut and tie model (Figure 12). As a simplification an angle of the struts of $45^{\circ}$ may be assumed.

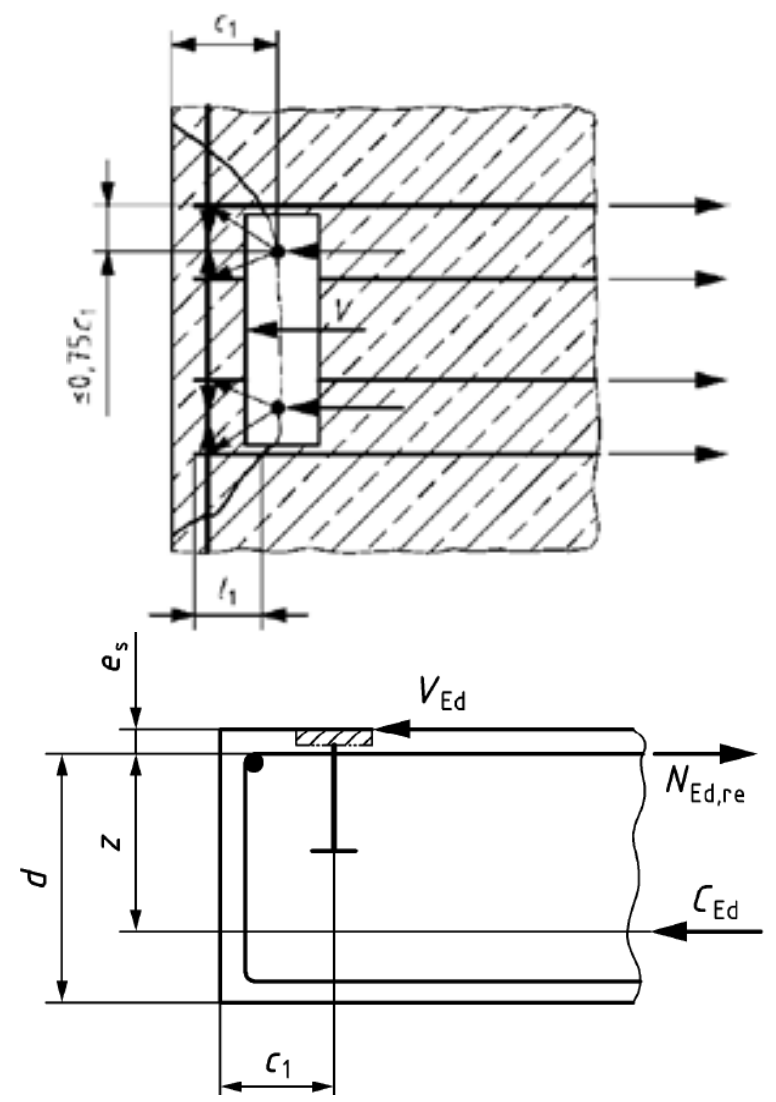

Figure 12: Simplified strut-and-tie model for anchor reinforcement by EN1992-4 [1]

As per the strut-and-tie model, the characteristic resistance $V_{R k, r e}$ of the supplementary reinforcement of one fastener in case of an anchorage failure in the concrete edge break-out body is given by:

$$
V_{R k, r e}=\sum_{n} V_{R k, r e}^{0}
$$

With

$$
V_{R k, r e}^{0}=\frac{l_{1} \cdot \pi d_{s} \cdot f_{b k} / \alpha}{x} \leq \frac{f_{y k} A_{s, r e}}{x}
$$

Where,

$n=$ number of legs of the anchor reinforcement effective for one fastener

$l_{1}=$ anchorage length $=$ distance from the intersection of theoretical crack and the rebar to the stirrup end

$d_{s}=$ diameter of rebar

$f_{b k}=$ characteristic bond strength $=1.5 f_{b d}$

$f_{b d}=$ design bond strength according to EN1992-1-1 [5]

$f_{y k}=$ characteristic yield strength of rebar 
$A_{s, r e}=$ Area of reinforcing bar used as stirrup $\alpha=$ influencing factor that assumes a value of 0.7 for hooked rebar and 1.0 for straight rebar $x$ is the factor to consider for the lever arm between the reinforcement and the applied shear load (compare Figure 12)

$$
x=\left(1+\frac{e_{s}}{z}\right)
$$

$e_{s}=$ distance between reinforcement and shear force acting on a fixture

$z=$ internal lever arm of the concrete member that is approx. equal to $0.85 d$

$d=\min \left(\right.$ depth of concrete member, $2 h_{e f}, 2 c_{l}$ )

If the evaluated failure load corresponding to the concrete edge breakout in unreinforced concrete is $V_{R k, c}$ then as per EN1992-4 [1], the failure load corresponding to concrete edge failure for an anchorage in with supplementary reinforcement is given as

$$
V_{R k}=\max \left(V_{R k, c} ; V_{R k, r e}\right)
$$

\subsection{Comparison with experimental failure loads}

The failure loads predicted as per the EN1992-4 [1] model were converted to the mean resistance values for different anchor groups tested and compared with the experimental mean failure loads. Although EN1992-4 [1] recommends considering the failure crack initiating from the front anchor row, here the experimentally obtained mean failure loads are compared with the analytical failure loads evaluated using EN1992-4 [1] model considering crack once from front anchor row and once from back anchor row.

In case of groups $1 \times 2$ (Figure 13), the mean test failure load for the groups tested in unreinforced concrete matches reasonably well with the evaluated mean failure load value. However, due to a short anchorage length, in no case any contribution from stirrups is considered by the EN1992-4 [1] model. The analytically evaluated failure capacity for the anchor group $1 \times 2$ is independent of the diameter of stirrups and is equal to the capacity evaluated in unreinforced concrete. Although, the EN1992-4 [1] model seems to under-predict the measured failure loads of the group, given the unreliability of the contribution of the rope action of edge reinforcement for this anchor group, the approach given in the model seems reasonable.

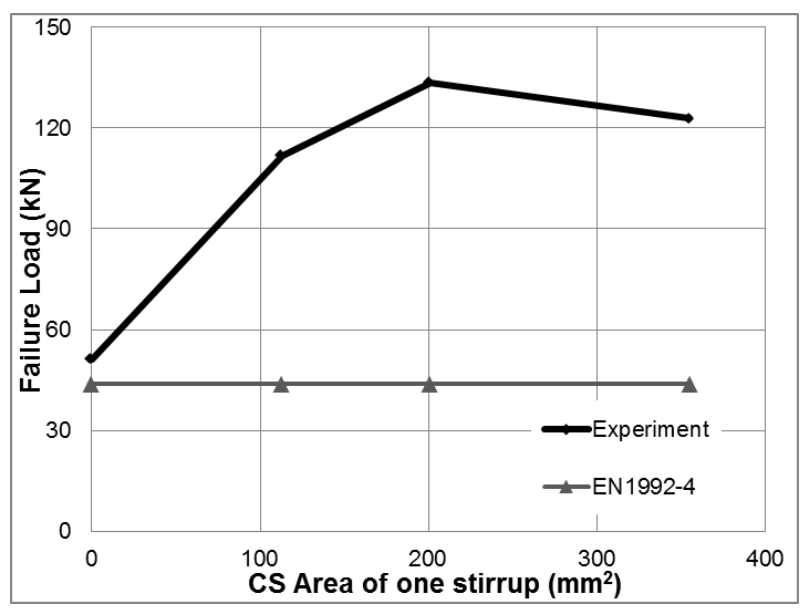

Figure 13: Comparison of mean failure loads obtained from the tests with the mean failure loads predicted by EN1992-4 [1] for groups 1x2

Figure 14 presents the comparison of experimentally obtained and analytically evaluated mean failure loads for the group $2 \times 2$, as a function of cross-sectional area of one stirrup, as calculated by EN1992-4 model considering crack once from front and once from back anchors. When the crack is assumed from front anchors, no stirrups are considered as effective. Consequently, the group capacity is always equal to the concrete capacity in unreinforced concrete evaluated from front anchors. When the crack is considered from back anchors, one stirrup on each side of the anchorage becomes effective. However, the stirrup contribution does not exceed that of concrete contribution until the case with $\mathrm{d}_{\mathrm{s}} 16+14$ bundled stirrups. Therefore, for the other three cases (unreinforced concrete, concrete reinforced with $\mathrm{d}_{\mathrm{s}}=12 \mathrm{~mm}$ stirrups and concrete reinforced with $d_{s}=16 \mathrm{~mm}$ stirrups), the capacity is the same as the concrete capacity in unreinforced concrete. It can be further observed that even in case of $d_{s} 16+14$ bundled stirrups the evaluated capacity is quite conservative compared to the experimentally obtained mean failure load. 


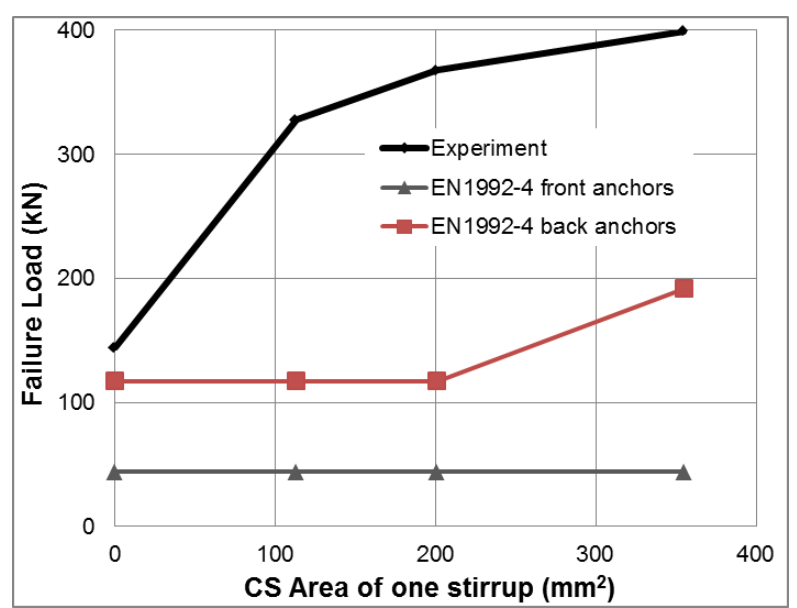

Figure 14: Comparison of mean failure loads obtained from the tests with the mean failure loads predicted by EN1992-4 [1] for groups 2x2

Figure 15 gives the comparison of experimentally obtained and analytically evaluated mean failure loads for group $4 \times 2$, considering crack once from front and once from back anchors. When the crack is considered from front anchors, again no stirrups are considered effective and hence the failure load in reinforced concrete is the same as that in unreinforced concrete. Obviously this is unrealistic and overly conservative compared to the experimentally obtained failure loads. When the crack is considered from the back anchors, stirrups within a distance of 0.75 times the edge distance of back anchor row $(=535 \mathrm{~mm})$ are considered as effective. Thus, two stirrups on either side of the anchorage are effective. For the case of $12 \mathrm{~mm}$ stirrups, the calculated failure load corresponding to reinforcement failure is less than the concrete edge failure load in unreinforced concrete and hence the failure no enhancement in the load-carrying capacity is obtained even when the crack is considered from back anchors. However, for the other two cases, the failure load increases due to the presence of reinforcement. The trend of calculated failure loads as a function of stirrup cross-section area shows that the failure load first remains constant and then rises sharply with the reinforcement. This trend is opposite to the actually obtained trend from experiments that display initially a very sharp rise in the failure load with reinforcement but later gets saturated.

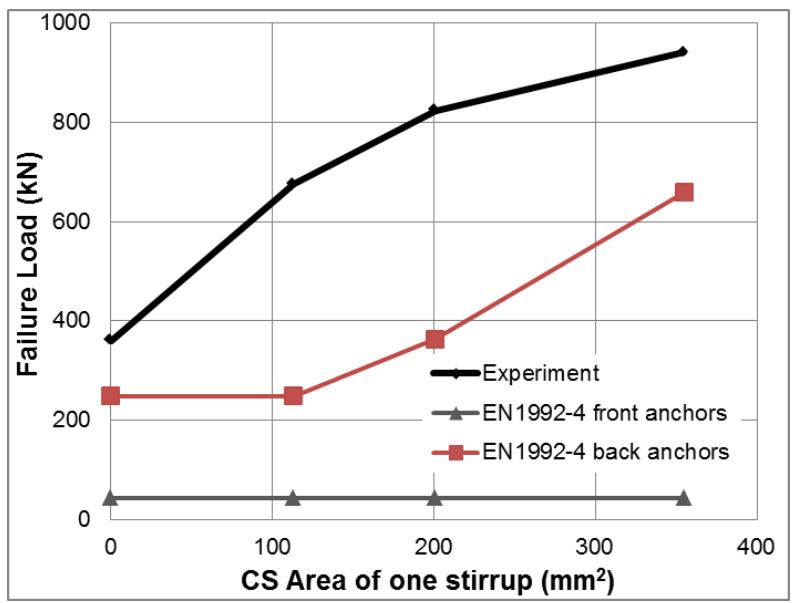

Figure 15: Comparison of mean failure loads obtained from the tests with the mean failure loads predicted by EN1992-4 [1] for groups 4x2

Group $2 \times 4$ is different from all the other groups in the sense that the distance between the outermost anchors in this case is $450 \mathrm{~mm}$ instead of $150 \mathrm{~mm}$ and that two reinforcing bars lie in between the outermost anchors unlike any other anchor group that was tested in this program. The comparison of failure loads obtained for group 2x4 using EN1992-4 model considering crack from front and back anchors is given in Figure 16. It may be noted that although, for this group, no tests were performed in concrete reinforced with $16 \mathrm{~mm}$ stirrups, the analytical failure loads for such a case are included in Figure 16. The dashed line shows a probable trend that the failure loads would have followed if tests were performed also in concrete reinforced with $16 \mathrm{~mm}$ stirrups. For this anchor group, considering the crack from the front anchors, the calculated anchorage length, $l_{1}$, is less than the minimum required anchorage length of $4 \mathrm{~d}_{\mathrm{s}}$ for the case of $16 \mathrm{~mm}$ and $16+14 \mathrm{~mm}$ bundled stirrups. For $\mathrm{d}_{\mathrm{s}} 12 \mathrm{~mm}$ stirrups, the calculated anchorage length is slightly larger than the minimum required anchorage length, which results in a small calculated value of anchorage resistance. However, since this resistance is smaller than the failure load corresponding to concrete edge failure, it does not lead to any increase in the failure load evaluated from the front anchors. Therefore, for this group, same as for previous cases, the reinforcement does not contribute to the failure load, as per the EN1992-4 model 
when assuming the crack from front anchors. While considering the crack from back anchors, two stirrups that lie in between the outermost stirrups and two stirrups at a distance of $25 \mathrm{~mm}$ from outermost anchors are considered effective. The comparison of experimental and analytical failure loads clearly indicate that the EN1992-4 approach for evaluating the capacity of anchor groups in reinforced concrete loaded in shear perpendicular to the edge is very conservative even when the crack is considered from back anchors.

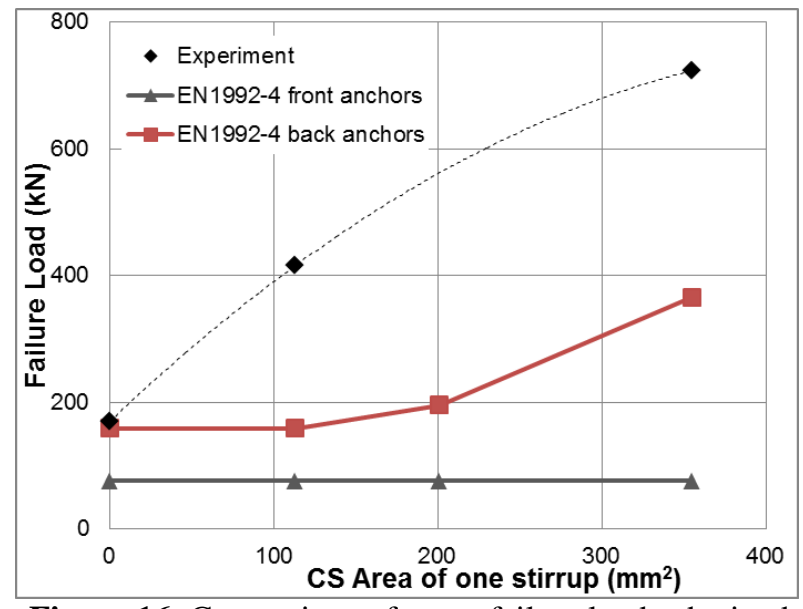

Figure 16: Comparison of mean failure loads obtained from the tests with the mean failure loads predicted by EN1992-4 [1] for groups 2x4

\section{ANCHOR STEEL FAILURE}

As mentioned earlier, as per the current standards [1-3], if the failure crack for concrete edge failure is assumed from the front anchor row, then all anchors of the group are considered to contribute towards steel failure [1] but if the failure crack for concrete edge failure is assumed from the back anchor row, then only the anchors in the last anchor rows are considered to contribute towards anchor steel failure [2-3].

In Figure 17, the theoretical mean failure load for anchor steel failure is compared with the experimental mean failure load obtained for group $4 \times 2$. The mean anchor steel failure load is calculated considering one, two, three and all four anchor rows taking up shear loads. It may be noted, however, that in this test program, anchor steel failure did not occur in any of the tests.

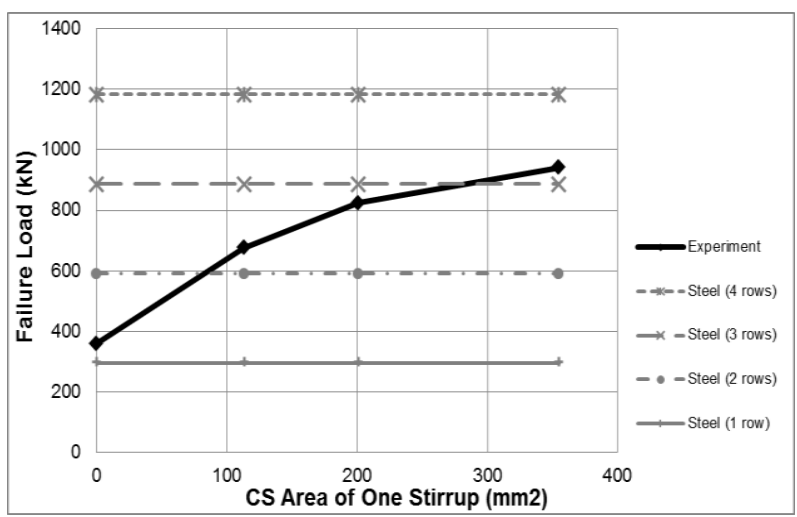

Figure 17: Comparison of mean failure loads obtained from the tests with the mean failure loads for anchor steel failure for the groups $4 \times 2$

From Figure 17, it is clear that the assumption of only one anchor row participating in steel failure, if the failure crack for concrete edge is assumed from the back anchor row, is definitely very conservative. The test results indicate that all the anchors take up shear loads, however, the contribution of each anchor row might be different.

However, since in the tests, anchor steel failure did not occur, the exact contribution of the anchors towards steel failure cannot be determined from these tests. Further experimental investigations are needed on multiple row anchorages loaded in shear towards the edge with the critical failure mode as anchor steel failure. Based on these tests, the current model for anchor steel failure can be improved.

In the accompanying paper, the aspect of anchor steel failure is investigated for multiple row anchorages loaded in shear towards the edge by the means of numerical simulations.

\section{CONCLUSIONS}

In this paper, the details and results of an experimental program carried out on anchor groups in unreinforced and reinforced concrete loaded in shear perpendicular to the edge are discussed. Anchor groups with up to four anchor rows perpendicular to the edge are tested in concrete with four different levels of shear reinforcement. The major conclusions 
derived from the results of the tests and analytical evaluations are:

1. The reinforcement in the form of edge reinforcement and stirrups can significantly increase the load-carrying capacity of anchorages against shear loads applied perpendicular to the edge. This is valid also for a relatively small amount of anchor reinforcement.

2. The failure crack in case of supplementary reinforcement failure initiates from the back row of anchors resulting in a high anchorage length of the stirrups, which increases their capacity. Furthermore, more stirrups are engaged by the crack.

3. For the anchor group with only one anchor row (group $1 \times 2$ ) and with a small edge distance, the stirrups could not be activated. A rise in failure load due to a rope action of the edge reinforcement was observed. However, this increase is unreliable and should not be accounted for in design.

4. Although increasing the area of the anchorage reinforcement results in an increase of the load carrying capacity of the anchorage in general, this increase is not unlimited. It is capped by strut failure (compression failure of concrete) or steel failure of headed studs.

5. The current models to evaluate failure loads for anchorages with more than one anchor row perpendicular to the edge in reinforced concrete loaded in shear perpendicular to the edge, are in general, over conservative.

6. For the tested anchor groups, the EN1992-4 model, in its current form (assuming crack from front anchors), does not consider the contribution of reinforcement.

7. The EN1992-4 model is very conservative even when the crack is assumed from the back anchors.

8. Because no cap on the load carrying capacity for strut failure is assumed in the model, the analytical failure loads have a tendency to be unconservative for high amounts of shear reinforcement in the concrete slabs (higher than provided in the tests)

9. There is a need to develop a more rational and reliable method to analytically evaluate the shear failure loads of anchorages with more than one anchor row in reinforced concrete.

10. It is also highlighted that even when the failure crack is initiated from the back anchor row, almost all the anchors participate in resisting this load through anchor steel failure.

Based on the test results reported in this paper, a model is developed to realistically predict the failure loads for the anchorages in reinforced concrete loaded in shear perpendicular to the edge. The details of the model are presented in the accompanying paper. Furthermore, in order to augment the test results and to evaluate the shear loads taken up by individual anchors, numerical simulations within the framework of fracture mechanics are performed using 3D FE software MASA developed at University of Stuttgart.

\section{ACKNOWLEDGEMENTS}

The presented project was funded by Electricite De France (EDF), Lyon, France and was also supported by AREVA Deutschland, Germany.

\section{REFERENCES}

[1] FprEN 1992-4. 2015. Eurocode 2: Design of concrete structures - Part 4 Design of fastenings for use in concrete, European committee for standardization, CEN/TC 250, Brussels.

[2] International federation for concrete (fib). 2011. fib Bulletin 58. Design of anchorages in concrete - Guide to good practice, fib Special Activity Group 4.

[3] American Concrete Institute. 2014. ACI 318: Building Code Requirements for Structural Concrete (ACI 318-14).

[4] Berger, W. 2015. Load-displacement behavior and design of anchorages with headed studs with and without supplementary reinforcement under tension load. $\mathrm{PhD}$ Thesis, Institute of Construction Materials, University of Stuttgart (In German). 